DOI: 10.17805/trudy.2017.2.6

\title{
ФИЛОГЕНЕТИЧЕСКИЕ ОСНОВЫ СТАНОВЛЕНИЯ МЫШЛЕНИЯ ВЫСШИХ ПОЗВОНОЧНЫХ"
}

\author{
И. А. Хватов \\ Московский институт психоанализа; Московский гуманитарный университет, \\ А. Ю. Соколов, Р. В. Желанкин \\ Московский институт психоанализа, \\ А. Н. Харитонов \\ Институт психологии Российской академии наук; Московский государственный \\ психолого-педагогический университет
}

Аннотация: В статье обобщаются основные данные обо особенностях мышления пресмыкающихся, рассматриваемые в качестве предпосылок становления мышления теплокровных позвоночных, включая человека. Обосновывается необходимость проведения комплекса экспериментальных исследований с применением унифицированных методик и критериев оценки для исследования основных аспектов мышления.

Ключевые слова: филогенез; эволюция психики; познавательные процессы; мышление животных; животные; позвоночные; пресмыкающиеся

\section{PHYLOGENETIC FOUNDATIONS OF THE MENTALITY OF HIGHER VERTEBRATES}

\section{A. Khvatov}

Moscow Institute of Psychoanalysis; Moscow University for the Humanities

A. Yu. Sokolov, R. V. Zhelankin

Moscow Institute of Psychoanalysis

A. N. Kharitonov

Institute of Psychology, Russian Academy of Sciences; Moscow State University of

Psychology and Education

Abstract: The paper summarizes basic data about the peculiarities of the mentality of reptiles, which are considered as pre-conditions for the formation of warm-blooded vertebrates' mentality, including humans. It also substantiates the need for a number of experimental studies with the application of unified methods and assessment criteria in order to research the basic aspects of mentality.

Keywords: phylogenesis; evolution of psyche; cognitive processes; mentality of animals; animals; vertebrates; reptiles

*Работа поддержана грантом РГНФ 17-06-00832а.

Financing RGSF 17-06-00832a. 
Элементарное мышление животных - это способность оперировать эмпирическими законами, связывающими предметы и явления внешнего мира, оперировать этими законами в новой для животного ситуации (относительно которой у него инстинкты или ранее сформированные навыки) для построения программы адаптивного поведенческого акта (Крушинский, 2009). Соответственно, именно благодаря мышлению животные осуществляют индивидуальную гибкую адаптацию к тем уникальным условиям среды, в которых она оказалась в данный момент времени с учетом максимального объема информации о себе и окружающей среде.

Начиная с XVIII века, исследователей, занимавшихся изучением поведения животных, интересовала проблема эволюционного происхождения мышления. Основная тенденция развития взглядов на эту проблему заключалась в постоянном смещение предполагаемого момента генезиса мышления на все более ранние периоды эволюции животных. Это связано с тем, что признаки мышления обнаруживались у представителей новых систематических групп. Так в начале XX века в работах В. Кёлера и Н.Н. Ладыгиной-Котс была продемонстрирована способность к мышлению человекообразных обезьян. Позже была доказана способность к мышлению ряда других видов млекопитающих (Зорина, Полетаева, 2003). Во второй половине XX века появились данные о том, что многие виды птиц по своему своим мыслительным способностям не только не уступают, но даже превосходят млекопитающих (там же).

Долгое время читалось, что мышление является достоянием психики только лишь теплокровных позвоночных - млекопитающих и птиц. Так в своей периодизации эволюции психики А. Н. Леонтьев относил этих животных к отдельной стадии - стадии интеллектуальной психики, предшествующей происхождению человеческого сознания (Леонтьев, 1972).

Между тем за последние десятилетия появляется все больше данных о наличии мыслительных способностей у хладнокровных высших млекопитающих (амниот). В ряде экспериментальных исследований показано, что пресмыкающиеся способны решать такие логические задачи, требующие наличия мышления, которые по своей сложности не только не уступают, но порою даже превосходят те, что доступны психике теплокровных позвоночных. Однако эти данные носят разрозненный и несистематизированный характер.

Таким образом, до сих пор остается нерешенным вопрос о том, когда и в связи с какими эволюционными факторами у представителей ранних хладнокровных позвоночных формировались способности к осуществлению мыслительных операций: абстрагирования, обобщения, символизации и др. Ответ на этот вопрос имеет фундаментальное значение для целостного понимания эволюции мышления у позвоночных, а также эволюционного происхождения человеческого сознания. 
Рептилии, птицы и млекопитающие произошли от общего предка, жившего порядка 280 млн лет назад. Соответственно, представители этих классов имеют много общего как в своей морфологической, так и в поведенческой организации. При этом современные рептилии по особенностям своего поведения и психической организации ближе всего (в сравнении с млекопитающими и птицами) стоят к общим предкам трех вышеуказанных отрядов позвоночных. Однако исследований когнитивных способностей пресмыкающихся, позволяющих сравнивать их с аналогичными способностями теплокровных позвоночных, к настоящему моменту имеется еще крайне мало. Отсутствует целостная концепция, описывающая и объясняющая эволюцию мышления у пресмыкающихся.

Между тем, изучение психики именно этой группы животных принципиально важно для ответа на вопрос, в каких условиях и под влиянием каких факторов происходило формирование элементарного мышления птиц и млекопитающих. Именно в ходе эволюции ранних высших позвоночных (амниот), с которыми наибольшее сходство имеют современные пресмыкающиеся, закладывались предпосылки формирования как морфофизилогической, так и психической организации более поздних видов. Соответственно, изучение этой группы животным имеет фундаментальное значение для понимания общего хода эволюции мышления и когнитивных способностей в целом у высших позвоночных. В конечном счете, эти предпосылки привели к формированию сознания современного человека.

Кроме того, важно также расширение методической базы когнитивных исследований: исследование применимости классических экспериментальных процедур и оборудования к новым объектам исследования, а также разработка качественно новых методов и экспериментальных установок.

Обобщая взгляды различных авторов на природу элементарного мышления животных, следует выделить основные аспекты проявления данного феномена:

1. Мышление позволяет решать такие задачи и адаптироваться к таким изменениям среды, с которыми индивид не сталкивался ранее в ходе своего онтогенеза;

2. Мышление позволяет осуществлять обобщение и абстрагирование, т. е. выделять и фиксировать относительно устойчивые, инвариантные свойства предметов и их отношений в процессе обучения и приобретения опыта;

3. Мышление позволяет предвидеть события и результаты собственных действий и планировать сообразно конкретным условиям внешней среды;

4. Мышление позволяет учитывать поведение сородичей - соверша- 
емые ими действия и их последствия (см.: Зорина, Полетаева, 2003).

Вышеперечисленные признаки мышления исследовались преимущественно на млекопитающих - причем, в основном на приматах. В последние десятилетия появилось также много работ, посвященных познавательным процессам у птиц. В сравнении с этими экспериментами, посвященными элементарному мышлению пресмыкающихся в современной научной литературе встречается мало.

К основным направлениям изучения элементарного мышления у рептилий относятся:

-Изучение пространственной ориентации в незнакомых условиях, а также перенос ранее приобретенных навыков в новые условия. Современные данные показывают, что пресмыкающиеся способно решать пространственные задачи (ориентацию в лабиринте, поиск обходного пути) с опорой на множество различных сигналов разных модальностей, формировать когнитивные карты пространства, а также переносить полученный опыт в новые ситуации (Wilkinson, Huber, 2012; Хватов, Соколов, Харитонов, 2015);

- Формирование дифференцировочных навыков на визуальные стимулы, обобщение признаков нескольких стимулов. Рептилии способны легко формировать дифференцировочные навыки на основе визуальной стимуляции, а также могут перестраивать ранее сформированные навыки не менее гибко, нежели млекопитающие (Wilkinson, Huber, 2012). К примеру, анолисовые ящерицы сформировали дифференцировочный навык выбора правильного отверстия в проблемном ящике с опорой на разные визуальные символы на поверхности крышек, которые им необходимо было открыть (Leal, Powell, 2011);

- Экстренное решение новой задачи по добыванию пищи. Существуют отдельные эксперименты, показывающие, что рептилии способны экстренно решать задачи по добыванию пищи, с которыми сталкиваются первый раз, формируя в дальнейшем устойчивый навык. Так черепахи вида Pseudemys nelsoni продемонстрировали способность опрокидывать прозрачные пластиковые бутылки для достижения приманки. Белогорлые вараны продемонстрировали способность открывать навесные дверцы для добычи корма из прозрачных пластиковых трубок (Wilkinson, Huber, 2012):

-Игровое поведение. В ходе игрового поведения животные переносят локомоторные и манипулятивные навыки, полученные в ходе игры с биологически нейтральным объектом, в ситуации, где аналогичные навыки будут необходимы для решения задач по достижению приманки. Было доказано наличие игрового поведения у черепах, включая совместные игры нескольких особей. Также, исходя из наличия сложного роди- 
тельского поведения, высказываются предположения о возможном наличии игры у крокодилов (Wilkinson, Huber, 2012);

- Научение по подражанию. Существуют данные, свидетельствующие, что игуаны, змеи и черепахи способны следить за направлением взгляда других представителей своих видов (Wilkinson, Huber, 2012). Также была экспериментально доказана способность к формированию навыков решения различных экспериментальных задач путем наблюдения за тем, как аналогичную задачу решает другой представитель вида, у угольных черепах и бородатых агам (там же).

Отдельно следует упомянуть о классических экспериментах на экстраполяцию (решение задачи на обнаружение обходного пути при достижении пищевой приманки), проводившихся в лаборатории Л.В.Крушинского на различных видах пресмыкающихся, птиц и рептилий. По своей способности решать задачу на экстраполяцию (находить обходной путь), т. е. по процентному соотношению правильных ответов в первой пробе, черепахи и зеленые ящерицы стояли выше большинства видов птиц за исключением врановых (Крушинский, 2009).

Имеющиеся эмпирические данные свидетельствуют о наличии у пресмыкающихся всех четырех вышеперечисленных аспектов мышления. Тем не менее, эти данные скудны, носят разрозненный характер, а также проводились на небольшом числе лабораторных видов рептилий. На сегодняшний день не предпринималось попыток сравнительного исследования элементарного мышления пресмыкающихся с применением унифицированных экспериментальных процедур и критериев оценки поведения параллельно на основных представителях пресмыкающихся. До сих пор отсутствует целостная концепция, позволяющая обобщить имеющиеся на настоящий момент данные и системно описывающая и объясняющая ход эволюции элементарного мышления у пресмыкающихся (основных направлений и факторов эволюционного процесса), а также предпосылки формирования психики теплокровных позвоночных.

Таким образом, в качестве перспективной задачи современной сравнительной психологии необходимо обозначить комплексное изучение основных аспектов элементарного мышления у пресмыкающихся с применением унифицированных экспериментальных процедур и критериев оценки, а также создание концептуальной модели, описывающей генезис и эволюцию элементарного мышления пресмыкающихся и предпосылки формирования мышления теплокровных позвоночных, включая человека.

\section{СПИСОК ЛИТЕРАТУРЫ}

Зорина, 3. А., Полетаева, И. И. (2003) Зоопсихология. Элементарное мышление животных. М. : Аспект Пресс. 
Крушинский, Л. В. (2009) Биологические основы рассудочной деятельности: Эволюционный и физиолого-генетический аспекты поведения. 3-е изд. М. : Либроком.

Леонтьев, А. Н. (1972) Проблемы развития психики. 3-е изд. М. : Моск. гос. университет.

Хватов, И. А., Соколов, А. Ю., Харитонов, А. Н. (2015) Схема собственного тела у змей Lampropeltis triangulum campbelli // Экспериментальная психология. Том 8. № 2. С. 119-138. doi: 10.17759/exppsy.2015080209

Leal, M., Powell B. J. (2011) Behavioural flexibility and problem-solving in a tropical lizard // Biology Letters. doi: 10.1098/rsbl.2011.0480

Wilkinson, A., Huber, L. (2012) Cold-Blooded Cognition: Reptilian Cognitive Abilities // The Oxford Handbook of Comparative Evolutionary Psychology / Ed. by T.K.Shackelford, J.Vonk. Oxfgord, 2012. doi:10.1093/ oxfordhb/9780199738182.013.0008

Дата поступления: 15.04.2017 2.

Хватов Иван Александрович - кандидат психологических наук, заведующий Научно-образовательным центром биопсихологических исследований Московского института психоанализа, доцент кафедры общей психологии и истории психологии Московского гуманитарного университета. Адрес: 111395, Россия, г. Москва, ул. Юности, д. 5. Тел.: +7(499) 37467-20. Эл. адрес: lab_bpi@inpsycho.ru

Соколов Алексей Юрьевич - кандидат биологических наук, старший научный сотрудник Научно-образовательного центра биопсихологических исследований Московского института психоанализа. Адрес: 121170, Россия, г. Москва, Кутузовский проспект, д. 34, стр. 14. Эл. адрес: lab_bpi@ inpsycho.ru

Желанкин Роман Викторович - младший научный сотрудник Научно-образовательного центра биопсихологических исследований Московского института психоанализа. Адрес: 121170, Россия, г. Москва, Кутузовский проспект, д. 34, стр. 14. Эл. адрес: lab_bpi@inpsycho.ru

Харитонов Александр Николаевич - кандидат психологических наук, старший научный сотрудник Института психологии Российской Академии наук, ведущий научный сотрудник Московского государственного психолого-педагогического университета. Адрес: 129366, Россия, г.Москва, ул. Ярославская, д. 13. Тел.:+7(495) 682-91-51.Эл. адрес: lab_bpi@ inpsycho.ru 
Khvatov Ivan Aleksandrovich, Candidate of Psychology, Director, Centre for Science and Education of Biopsychological Studies, Moscow Institute of Psychoanalysis; Associate Professor, Department of General Psychology and History of Psychology, Moscow University for the Humanities. Postal address: 5, Yunosti St., Moscow, Russian Federation 111395. Tel: +7 (499) 374-67-20. E-mail: lab_bpi@inpsycho.ru

Sokolov Aleksei Yurievich, Candidate of Biology, Chief Research Scientist, Centre for Science and Education of Biopsychological Studies, Moscow Institute of Psychoanalysis. Postal address: 34, Bldg. 14, Kutuzovsky Ave., Moscow, Russian Federation 121170.E-mail: lab_bpi@inpsycho.ru

Zhelankin Roman Viktorovich, Junior Research Scientist, Centre for Science and Education of Biopsychological Studies, Moscow Institute of Psychoanalysis. Postal address: 34, Bldg. 14, Kutuzovsky Ave., Moscow, Russian Federation 121170.E-mail: lab_bpi@inpsycho.ru

Kharitonov Aleksandr Nikolaevich, Candidate of Psychology, Chief Research Scientist, Institute of Psychology, Russian Academy of Sciences; Leading Research Scientist, Moscow State University of Psychology and Education. Postal address: 13, Yaroslavskaya St., Moscow, Russian Federation 129366. Tel.:+7(495) 682-91-51.E-mail: lab_bpi@inpsycho.ru

\section{Для цитирования:}

Хватов И. А., Соколов А. Ю., Желанкин Р. В., Харитонов А. Н. Филогенетические основы становления мышления высших позвоночных [Электронный ресурс] // Научные труды Московского гуманитарного университета. 2017, № 2. URL: http:// journals.mosgu.ru/trudy/article/view/452 (дата обращения: дд.мм.гг.). DOI: 10.17805/ trudy.2017.2.6 